\title{
Historia de la Medicina: Sir William Osler
}

\author{
History of Medicine: Sir William Osler \\ José Edmundo Lizardo Wildt, ${ }^{1}$ Mariani Espinal Suarez. ${ }^{2}$ \\ ${ }^{1}$ Estudiante Octavo Año, Carrera de Medicina, Universidad Católica Nuestra Señora Reyna de la Paz; \\ ${ }^{2}$ Médica General; Residente Primer Año, Postgrado de Pediatría, Universidad Autónoma de Honduras (UNAH); Tegucigalpa.
}

\section{INTRODUCCIÓN}

Sir William Osler es uno de los médicos de más influencia e importancia en la historia de la medicina. Hoy a los 102 años de su muerte queremos reconocer su legado como padre de la medicina moderna que revolucionó la enseñanza en la medicina, creador del primer hospital universitario y de los postgrados en el área de la salud en Estados Unidos.

\section{ANTECEDENTES}

William Osler nació en Canadá en el pequeño pueblo de Bond Head Ontario el 12 de julio 1849. Era el octavo hijo de una familia compuesta por Featherstone Lake Osler y Ellen Pickton Osler ambos galeses que viajaron desde Gran Bretaña a Canadá como misioneros anglicanos. ${ }^{1-3}$ En 1857 la familia se trasladó a Dundas, una población un poco más grande, donde el joven William inició su formación caracterizándose por ser un estudiante discreto. Su verdadero interés por el estudio empezó cuando fue enviado a la escuela episcopal de Weston debido a la influencia que recibió de sus dos primeros mentores; el reverendo William Johnson director de la escuela, ministro anglicano, naturista exquisito, conocedor de la literatura clásica quien le regaló el libro Religio Medici de sir Thomas Brown, marcando sobre el joven Willie el interés en las ciencias biológicas. ${ }^{1,3,4}$ Su segundo mentor fue el Dr. James Bovell, médico de la escuela de Weston, quien se educó en el Guy's Hospital en Londres bajo la influencia de los grandes médicos británicos como Bright, Hodgkin y Addison. Bovell tenía un microscopio y una biblioteca excelente, de tal manera que esta doble influencia hizo cambiar de opinión al joven Willie quien quería ser ministro anglicano como su padre. ${ }^{1-3}$

La ciudad de Montreal en la que Osler inició sus estudios tenía una población de 150,000 habitantes y la universidad de McGill era la mejor de Canadá con una biblioteca de 4000 volú-

Recibido: 25-05-2020 Aceptado para publicación 30-04-2021

Dirección para correspondencia: Dr. José E. Lizardo W.

Correo electrónico:joseedmundo21@gmail.com

Declaración de relaciones y actividades financieras y no financieras y conflictos de interés: ninguno. menes. Además contaba con un museo tanto de anatomía como de patología con énfasis en la disección y la práctica hospitalaria se realizaba en el Montreal General Hospital, de tal manera que McGill en América era superada únicamente por Harvard en Boston y Universidad de Pennsylvania. ${ }^{1,5}$ En realidad, pocas instituciones de Norte América ofrecían mejores instalaciones y acceso a hospitales de niveles más altos. Los requisitos de entrada eran más elevados que de todas las universidades de Norte América. La facultad tenía periodos lectivos más largos y exigía que los estudiantes siguieran cursos en sucesión y no desordenadamente. También exigía 4 años de formación en lugar de los dos o tres años habituales. En los dos últimos años, un estudiante de medicina dedicaba al menos doce meses a trabajar en casos médicos y quirúrgicos en el Hospital General de Montreal y casos obstétricos en Lying-In Hospital, de tal manera que McGill era una de las dos universidades canadienses reconocidas por el colegio real de médicos británicos. ${ }^{14,5}$

El joven Willie ingresó a la Escuela de Medicina McGill donde encontró su tercer mentor, el maestro Palmer Howard, quien había realizado estudios de postgrado en Europa. Howard fue el más erudito y científico de sus profesores con quien compartían el interés por las necropsias y a cuya consulta externa asistía diariamente. El entusiasmo de Howard era contagioso y estimulante; tan así que estudiaban todas las noches estableciendo una relación filial y de admiración mutua. ${ }^{1,5}$ La medicina de Montreal había adoptado la costumbre británica que los alumnos internos reseñaran los casos interesantes del hospital y los publicasen en una revista local por lo cual Osler hizo sus primeras publicaciones en Canadá Medical Journal en 1871 sobre la exeresis de un tumor de mama, una fisura anal, una angina de Ludwig, una nefritis supurativa y una muerte por pleuroneumonía. En 1872 Osler presentó su tesis de graduación "investigación de las causas de muerte de 20 necropsias"; su exposición en el anfiteatro fue juzgada como distinguida por su originalidad e investigación y le concedieron un premio especial en libros. ${ }^{1,5}$

Hondamente impresionados por el potencial que había mostrado, los profesores de Osler querían que se quedase en McGill. Por lo cual comentó el asunto con Palmer Howard que le aconsejó que mejor debía hacerse especialista. Sin embargo, no había oportunidades para la formación como residente en Canadá ni en ninguna parte de Estados Unidos por lo que 
Osler, como miles de estudiantes americanos, tendría que viajar a Europa para realizar su especialización. Con 22 años, viajó a Londres donde se inscribió en el curso de fisiología y patología práctica ofrecido por John Burdon Sanderson, realizando visitas hospitalarias en el famoso Guy's Hospital. Además, asistió a las sesiones clínicas de Charles Murchinson en St. Thomas Hospital y se matriculó en el University College Hospital donde conoció a Erasmus Wilson, Tilbury Fox, Charlton Bastian, Sydney Ringer, Sir William Jenner y Sir Henry Thompson. Partió de Inglaterra en octubre del 1873 no sin antes conseguir el certificado del Royal College of Physicians. ${ }^{1,2,4,5}$ Osler llegó a Berlín donde se matriculó en clases diarias de alemán y asistió a clases al mejor Hospital de Berlín, el Charite Royal, siendo alumno de Ludwig Traube, FT Von Frerichs y de Rudolph Virchow quien todos los lunes por la mañana realizaba una necropsia completa con tanto cuidado y minuciosidad que duraba cuatro horas. Posteriormente viajó a Austria al Hospital General de Viena Allgemeine Krakenhaus, donde estudió Pediatría con Herman Wiederhoffer, Dermatología con Ferdinand Hebra, enfermedades del oído con Adam Politzer y Patología con Karl Rokitansky. ${ }^{1,2,4-6}$

Regresó a McGill en julio de 1874 como profesor de medicina con 25 años de edad. Era más joven que muchos de sus alumnos con quienes publica algunos casos especialmente de anemia perniciosa, Enfermedad de Hodgkin, Corea de Sydenham, endocarditis reumática, tisis fibroide del pulmón, meningitis tuberculosa, empiemas y cálculos de la vesícula. En 1879, durante un encuentro de la Asociación Médica de Ontario, Osler realizó una conferencia titulada "The Medical Anatomy of the Brain" y describió 25 especímenes de enfermedades neurológicas como tumores cerebrales, accidentes cerebro vasculares, hemorragia cerebral y casos de esclerosis múltiple. ${ }^{1,5}$ Osler de su propio dinero encargó a París 15 microscopios Hartnack para sus estudiantes y con estos instrumentos impartió por primera vez en América un curso práctico de patología realizando él y sus estudiantes todas las necropsias del Hospital General de Montreal. En 1881 viajó al Séptimo Congreso Internacional a Londres junto con Howard conociendo a James Paget, Louis Pasteur y Moritz Kaposi, de tal manera que la Royal College of Physicians le concede el honor de hacerlo miembro, distinción que solo otros dos canadienses tenían. En 1884 McGill se encontraba en la primera fila de las universidades de Norte América y Osler viajó a Berlín al Charite Royal donde visitó a sus profesores Virchow y Von Frerichs, además conoció a Koch, descubridor del bacilo del Carbunco y Karl Friedlander que descubrió el Neumococo. Continúo su visita a Leipzig para estudiar sobre fisiología y bacteriología con Carl Ludwig y Karl Weigert. Estando en Leipzig, recibió una carta de James Tyson decano de la Facultad de Filadelfia con la propuesta para una cátedra en Pensilvania. ${ }^{1,5}$

El Hospital de Pensilvania fundado en 1751 y la Facultad de Medicina fundada en 1765, eran los establecimientos más antiguos del país. En sus primeros 120 años la Facultad de Medicina de la Universidad de Pensilvania solo había nombrado a un profesor que no fuese de Pensilvania o alumno de la universidad. Osler al llegar a Filadelfia organizó las reuniones clínico-patológicas, estudió 410 casos de Corea de Sydenham, publicó sobre endocarditis bacteriana subaguda, valvulitis mitral, afasia, malaria y apendicitis. Participó en la Fundación "The Association of American Physicians" (AAP) y se relacionó con los más grandes médicos de Filadelfia como Gross, Agnew, Stille, Wood, Hays, Leidy, Kreen, Mitchell, Pepper y Tyson. En Filadelfia empezó a ser consultado tanto por médicos como por parientes de médicos en camino a convertirse en médico de médicos. La salida de Osler de Filadelfia a Baltimore fue más fácil ya que recibió la visita de John Shaw Billings a quien había conocido en 1881 en un congreso internacional en Londres. El Dr. Shaw Billings era el fundador en 1865 de la Biblioteca Nacional de Bethesda y tenía la idea de organizar una nueva escuela de medicina moderna con tendencia a la investigación. Le ofreció el puesto de jefe del Departamento de Medicina Interna por lo que Osler decidió trasladarse rápidamente a Baltimore..$^{1-6}$

Johns Hopkins era un financista millonario de Baltimore que hizo una donación de 3.5 millones de dólares para la fundación de la mejor facultad de medicina y el mejor hospital de Estados Unidos. Los encargados para llevar a cabo este proyecto eran Daniel Colt Gilman, médico de Yale, y John Shaw Billings. médico académico fundador de las bibliotecas de medicina y del índex medicus, quienes seleccionaron inicialmente a Osler y al patólogo William Welch que se había entrenado en Alemania con Julius Cohnheim. Posteriormente Osler contrató a William Halstead como cirujano y a Howard Kelly como ginecólogo. Estos hombres del Hopkins, liderados por Osler, iniciaron el Johns Hopkins Hospital Bulletin y Johns Hopkins Hospital Reports, donde comenzaron a difundir sus conocimientos médicos al mundo. John Singer, el retratista más famoso de su generación, plasmó la influencia de estos médicos en un cuadro que títuló "The Four Doctors". 1-3,5,7

Osler inició en el Johns Hopkins la transformación de la educación médica en América. Creó el primer Hospital Universitario, modificó el currículo, endureció los requerimientos de admisión, solo aceptaban candidatos altamente calificados que debían tener estudios de 4 años que incluyeran dos años en biología, química y física; además debían saber leer francés y alemán. Aumentó el currículo de dos a cuatro años con rotaciones clínicas por bloques en tercer y cuarto año que incluía de tres a cuatro meses en medicina interna, cirugía, ginecología y pediatría. Se crearon las residencias médicas. El término se deriva de que en esa época los internos seleccionados para el entrenamiento de cada especialidad hacían parte del personal médico y además vivían en el mismo lugar donde estudiaban y trabajaban.

La dedicación del estudio debía ser absoluta, inmersos totalmente en su entrenamiento, solo aceptaban médicos solteros. Los residentes no debían tener distracciones y con regulaciones casi monásticas, concepto que había asimilado del Hospital de Viena Allgemeine Krakenhouse implementado por el Dr Billroth. ${ }^{1,3,5}$ Durante el invierno de 1890-91, con 42 años, surgió en Osler la idea de escribir un libro que títuló "The Principles and Practice of Medicine", que fue publicado por Appleton en marzo 1892 con 1050 páginas. La primera tirada de 3000 ejemplares se vendió en 2 meses y en los primeros dos años vendió 14000 ejemplares. Este fue el primer libro moderno de 
Medicina Interna, con 16 ediciones en un periodo de 55 años y Osler como revisor personal en las primeras 7 ediciones. Se ha considerado como el tratado más influyente de medicina interna, llegando a imprimirse más de 500,000 copias y se tradujo al francés, ruso, alemán, chino y español. ${ }^{1-8}$

Meses después de la publicación del libro, se casó con Grace Revere, tuvieron dos hijos, Paul que murió a los meses de nacido y Edward que murió en 1917, en la primera guerra mundial. Para el año 1898 había recibido el Doctorado Honorifico de McGill, Jefferson Medical College, Trinity College de Toronto, de las universidades escocesas de Aberdeen y de Edimburgo. En 1904 se publicó la primera edición de la obra maestra "Aequanimitas" que contiene 22 conferencias pronunciadas por Osler con ocasión de aperturas y clausuras de cursos. ${ }^{1,2,5,8}$

En abril 1904, Harvard honró a Osler con un doctorado honoris causa y el rector Elliot le ofreció una cátedra para el siguiente año, que Osler rechazó. El 16 de julio viajó en compañía de Harvey Cushing, su discípulo y amigo, a Londres, ya que también la Asociación Médica Británica lo había honrado con un doctorado honoris causa y Sir John Burdon Sanderson, antiguo tutor de Osler durante su entrenamiento en Londres, le pidió que aceptara el puesto de Profesor Regius de Medicina de Oxford. Este título fue establecido por el Rey Henry VIII en 1546, por lo que debía tener el visto bueno del Primer Ministro que en esa época era Arthur Balfour. Osler llegó a Oxford el 27 de mayo de 1905 y no solo sería el primer canadiense sino el primer no inglés en recibirlo. ${ }^{1-5,7}$

En 1906, fue uno de los fundadores de la Asociación de Médicos de Gran Bretaña e Irlanda. Además, ese mismo año fue el fundador de Quarterly Journal of Medicine y en 1907, junto con Tom McCrae, Hideyo Noguchi, Maude Abbott y Harvey Cushing, publicaron el libro "A System of Medicine" de 1000 páginas, que en América se llamó "Osler Modern Medicine". En junio de 1911, el Primer Ministro H.H. Asquith le concedió el título de Baronet incluyéndolo en la lista de honores que acompañan la coronación de Jorge V. por lo que a partir de esa fecha se convirtió en Sir William Osler, primer norteamericano en obtener este título honorifico, que pasaría a su hijo Edward y luego a sus herederos. Para esa época, a solicitud del Rey era el médico del heredero al trono Eduardo Príncipe de Gales y de la esposa e hijo del primer Ministro Herbert Henry Asquith. ${ }^{1-3,5,7}$ El martes 4 de agosto de 1914, el imperio británico entró en guerra, Edward no había cumplido los 18 años, pero para 1916 ya tenía 20 años por lo que fue asignado como teniente de la 59 Brigada de la Real Artillería. En los primeros meses no había sufrido ni un rasguño, pero el miércoles 29 de agosto 1917 en Ypres, a las 04:30 súbitamente explosionó un proyectil alemán de 107 milímetros a 5 metros de distancia, recibiendo Edward metralla en el pecho, abdomen y muslo. Fue operado por dos cirujanos de New York, William Darrada y George Brewer, quienes cerraron dos perforaciones del intestino grueso y le transfundieron sangre, pareció recuperarse y estuvo muy bien por 5 horas, pero lamentablemente falleció. Los Cirujanos americanos inmediatamente que llegó el joven Osler enviaron un mensaje al Dr. Harvey Cushing que se encontraba como médico militar en el frente logrando llegar a tiempo para la intervención, vigilándole el pulso durante la cirugía y en el postoperatorio hasta su muerte. Fue enterrado justo afuera envuelto en la bandera británica. Cushing entristecido al pensar en su padre, cortó un botón de la guerrera del muchacho. La fantástica coincidencia que Cushing estuvo presente para atender a Edward fue un verdadero consuelo, al menos los Osler supieron cómo había muerto su hijo, que habían hecho todo lo posible para salvar su vida y que había tenido un entierro decente. 1-3,5,7,9

Los Osler temían desde que Edward se fue al frente, que ese momento llegaría tarde o temprano. Por esta razón habían vivido con tanta zozobra en espera de malas noticias en los últimos 6 meses. Una vez que estas llegaron, ambos cayeron en una gran depresión y Sir William no se pudo recuperar. En 1918 y 1919 sufrió una serie de procesos infecciosos bronquiales que en diciembre 1919 se agravaron con una neumonía que se complicó con un empiema con ruptura a la cavidad pleural falleciendo el 29 de diciembre 1919. El cuerpo fue incinerado y las cenizas permanecieron en la Biblioteca de Oxford; sin embargo, las instrucciones de Osler era que las cenizas, junto con sus libros, fueran enviadas a McGill sobre todo para que sus libros formaran la base de una biblioteca médica y se convirtiera en un centro de investigación. En 1928 se realizó el embalaje de 86 cajas con 8000 libros valoradas en 10,000 libras que junto con sus cenizas se encuentran en el edificio de la Facultad de Medicina de McGill y que constituye en la actualidad la Biblioteca Osleriana de Medicina de McGill, donde descansan las cenizas de Sir William Osler como las de su esposa. ${ }^{1,2,5-7}$

Grace Osler le pidió a Harvey Cushing que escribiese la biografía de su esposo. Cushing para ese entonces era el más famoso neurocirujano del mundo. No obstante, invirtió durante 5 años escribiendo muy temprano por las mañanas y todas las noches para entregar un escrito de un millón de palabras de prueba que Oxford University Press al final le convenció que redujese a 600,000 palabras, de tal manera que el libro se publicó en 1925 con 1400 páginas. La biografía fue un éxito tanto en Norte América como en el Imperio Británico y fue honrada en 1926 con el Premio Pulitzer a la mejor biografía del año. Existen tres biografías más sobre Osler, la de Maude Abbott, la de Charles Brayan y la última publicada por el historiador canadiense Michael Bliss en 1999. 1,2,4,7,9

El Dr. Osler gustaba mucho del género aforístico, sobre todo durante sus visitas hospitalarias, por lo que citaremos algunas de las más relevantes: "Ver enfermos sin leer libros es como navegar en el mar sin tener cartas de navegación, pero leer libros sin ver enfermos es como nunca navegar"; "La palabra mágica, el ábrete sésamo de todas las puertas, la piedra filosofal que vuelve oro todo lo que toca y aquellos de vosotros que sois mediocres los hará inteligentes y a los inteligentes brillantes, esa palabra es Trabajo".-6,10

\section{CONCLUSIÓN}

La vida de William Osler ilumina su época de modo sorprendente. Fue un eterno estudiante y un admirado maestro. Ejerció la medicina, enseñó medicina y escribió sobre ella en tres países donde atendió por igual ricos y pobres. 


\section{CONTRIBUCIONES}

Ambos autores participamos en igual medida en la recolección de la información y redacción del manuscrito. Ambos autores atendimos las recomendaciones editoriales y aprobamos la versión final manuscrito.

\section{AGRADECIMIENTOS}

A la Dra. Débora Wildt Rittenhouse, práctica clínica independiente, por la revisión crítica del manuscrito.

\section{REFERENCIAS}

1. Bliss M. William Osler una vida entregada a la medicina. Madrid: ERGON; 2006.

2. Young P, Finn BC, Bruetman JE, Emery JD, Buzzi A. William Osler: el hombre y sus descripciones. Rev méd Chile [Internet]. 2022 [consultado 8 abril 2021];140(9):1218-1227. Disponible en: http://www.scielo.cl/ scielo.php?script=sci_arttext\&pid=S0034-98872012000900018\&Ing=es. DOI:http://dx.doi.org/10.4067/S0034-98872012000900018.

3. González Vélez M. Sir William Osler. Desde el Nacimiento de los Hospitales Universitarios hasta la Satisfacción por la Medicina Moderna. CES Medicina [Internet] 2012[consultado 8 abril 2021];26(1):121129. Disponible en: https://revistas.ces.edu.co/index.php/medicina/article/view/1505 DOl:https://doi.org/10.216115/ces\%20med.v26i1.1505

4. Becker RE. Remembering Sir William Osler 100 years after his death: What can we learn from his legacy? Lancet [Internet]. 2014[consultado 8 abril 2021]; 384(9961):2260-3. Disponible en: https://pubmed.ncbi.nlm.nih. gov/25625399/ DOl:10.1016/S0140-6736(14)61887-0.

5. Iglesias A. Sir William Osler. Acta Med Col. [Internet] 2009 [consultado 10 abril 2020];34(25):282-90. Disponible en :htpp://www.actamedicacolom- biana.com/ojs/lndex.php/actmed/article/view/1714

6. Serra Valdes MA. Sir William Osler. El Padre de la Medicina Moderna. Aportes a la Reumatología. Rev Cub Reumatol [Internet]. 2015 [consultado 12 abril 2020];17(Suppl:1):162-168. Disponible en: http://scielo.sld.cu/ scielo.php?script=scl arttext\&pid=S1817-59962015000300014\&lng=es

7. Golden RL. William Osler at 150: An overview of a Life. JAMA [Internet]. 19992015 [consultado 12 abril 2020];282(23):2252-8. Disponible en: https:/l pubmed.ncbi.nlm.nih.gov/10605978/～DOI:10.1001/jama.282.23.2252. PMID:10605978

8. Buzzi A. Historia del tratado de Medicina Interna de William Osler. Medicina [Internet]. 2005[consultado 12 abril 2020];65(5):465-70. Disponible en: https:medicinabuenosaires.com

9. Raffensperger J.G. Harvey Cushing: A life in Surgery. J Pediatr Surg. 2006 Mar; 41(3): 609-611

10. Buzzi A. Los Aforismos de William Osler. Rev Aso Med Argent. [Internet]. 2011[consultado 12 abril 2020];124 (2):3-5. Disponible en : https:www. ama-med.org.ar 